\title{
The Carcinogenic Agent Diethylnitrosamine Induces Early Oxidative Stress, Inflammation and Proliferation in Rat Liver, Stomach and Colon: Protective Effect of Ginger Extract
}

\author{
Dina F Mansour ${ }^{1,2 *}$, Heba M I Abdallah'1, Bassant M M Ibrahim¹, Rehab R \\ Hegazy $^{1}$, Reham S E Esmail ${ }^{3}$, Lubna O Abdel-Salam ${ }^{4}$
}

\begin{abstract}
Background: Diethylnitrosamine (DENA), a well-known dietary carcinogen, related to cancer initiation of various organs. The present study investigated the deleterious mechanisms involved in the early destructive changes of DENA in different organs namely, liver, stomach and colon and the potential protective effect of GE against these mechanisms. Methods: Adult male albino rats were assigned into four groups. A normal control group received the vehicle, another group was injected with a single necrogenic dose of DENA $(200 \mathrm{mg} / \mathrm{kg}$, i.p) on day 21 . Two groups received oral GE (108 or $216 \mathrm{mg} / \mathrm{kg}$ ) daily for 28 days. Sera, liver, stomach and colon were obtained 7 days after DENA injection. Serum aspartate transaminase and alanine transaminase were detected as well as reduced glutathione (GSH), malondialdehyde, nitric oxide metabolites, interleukin $1 \beta$, tumor necrosis factor (TNF- $\alpha$ ), alpha-fetoprotein (AFP) and nuclear factorerythroid 2-related factor2 (Nrf2) in liver, stomach and colon. Histopathological studies and immunohistochemical examination of cyclooxygenase-2 (COX2) were conducted. Results: DENA induced elevation in liver function enzymes with significant increase in oxidation and inflammation biomarkers and AFP while decreased levels of Nrf2 in liver, stomach and colon were detected. Histologically, DENA showed degenerative changes in hepatocytes and inflammatory foci. Inflammatory foci displayed increased expression of COX2 in immunohistochemical staining. GE-pretreatment improved liver function and restored normal GSH with significant mitigation of oxidative stress and inflammatory biomarkers compared to DENA-treated group. AFP was reduced by GE in both doses, while Nrf2 increased significantly. Histology and immunostaining of hepatic COX-2 were remarkably improved in GE-treated groups in a dose dependent manner. Conclusion: GE exerted a potential anti-proliferative activity against DENA in liver, stomach and colon via Nrf2 activation, whilst suppression of oxidation and inflammation.
\end{abstract}

Keywords: Diethylnitrosamine- ginger extract- oxidative stress- inflammation- proliferation- liver- stomach-colon- Rat

Asian Pac J Cancer Prev, 20 (8), 2551-2561

\section{Introduction}

Ginger (Zingiber officinale) is a medicinal herb in Southeast Asia that consequently spread through the world as natural remedy for many diseases such as gastrointestinal, and rheumatic disorders (Afzal et al., 2001). Ginger extract and its active constituents stand behind the antioxidant, anti-inflammatory, and antimutagenic properties with accumulated evidence from in vitro, in vivo, and epidemiological studies (Rani et al., 2011; Prasad and Tyagi, 2015b). Gingerols, among the bioactive compounds in ginger that have prominent cancer preventive effects against gastric and colon cancer in vitro (Jeong et al., 2006; Brown et al., 2009; Prasad and Tyagi, 2015a) and skin cancer in vivo (Kim et al., 2005;
Mashhadi et al., 2013).

Nitrosamines embrace a wide category of environmental carcinogens present in smoked pickled fish, cheese, nitrite-cured meats, dried milk and alcoholic beverages or tobacco smoke. They are also formed in the acidic conditions of the stomach from nitrite precursors and amines present in food constituents or additives, residues of agricultural chemicals and pharmaceutical drugs (Mittal et al., 2006).

Nitrosamines are able to induce tumors in the majority of organs and systems (Bartsch and Montesano, 1984). Diethylnitrosamine (DENA) is one of the most significant hepatotoxicants and hepatocarcinogens. Amines are activated by reaction with nitrate, leading to $\mathrm{N}$-nitrosamines under the acidic medium of stomach

${ }^{1}$ Department of Pharmacology, Medical Division, National Research Centre, Bohoth st., 12622, Dokki, Giza, ${ }^{2}$ Department of Clinical Pharmacy and Pharmacy Practice, Faculty of Pharmacy, Ahram Canadian University, ${ }^{3}$ Department of Pathology, Faculty of Medicine, Fayoum University, ${ }^{4}$ Department of Pathology, Faculty of Medicine, Cairo University, Egypt. *For Correspondence: dinaf.mansour@gmail.com 
(Sadik et al., 2008; Janani et al., 2010).

Induction of hepatocyte injury with enhanced cell proliferation accompanied by hepatocellular necrosis is a well-established mechanism of carcinogenesis by several hepatocarcinogens such as DENA (Glauert et al., 2010; Qiu et al., 2011). Since DENA needs to be bio-activated by hepatic cytochrome P450 enzymes (CYP450), specifically CYP2E1, resulting in DNA-adducts, through an alkylation mechanism (Kang et al., 2007), inducing genetically altered hepatocytes during initiation (Vasquez-Garzon et al., 2013). This bio-activation process is a crucial step in initiation of carcinogenesis through subsequent oxidative stress and cellular injury (Kang et al., 2007; Sadik et al., 2008; He et al., 2012; Jayakumar et al., 2012). Moreover, the development of esophageal squamous-cell cancer (SCC) and gastric adenocarcinoma have been attributed to nitrosamines (Binato et al., 2008).

The potential chemopreventive role of different antioxidants on oxidative stress-induced tissue damage by wide range of carcinogens including DENA has been substantially investigated (Janani et al., 2010; He et al., 2012; Jayakumar et al., 2012).

The present study investigated the deleterious mechanisms that are involved in the early destructive changes induced by DENA in different organs namely, liver, stomach and colon. The study extended to test the potential protective effect of GE against these mechanisms.

\section{Materials and Methods}

\section{Animals}

Forty adult male Wistar albino rats weighing 180-200 $\mathrm{g}$ were utilized in the present study. Standard food pellets and tap water were supplied ad libitum. Animals and food pellets were obtained from the animal house colony of the National Research Centre (NRC, Egypt). Animals were cared for in accordance with the Guide for the Care and Use of Laboratory Animals (1996, published by National Academy Press, 2101 Constitution Ave. NW, Washington, DC 20055, USA) and the experiment was conducted in accordance with ethical rules for standard experimental animal studies and the Medical Research Ethics Committee (MREC) of the National Research Centre under approval number: 15130.

\section{Drugs and chemicals}

Diethylnitrosamine (DENA) was purchased from Sigma-Aldrich (Germany). DENA was injected intraperitoneally in a single necrogenic dose of $200 \mathrm{mg} / \mathrm{kg}$ (Tessitore, 1998; Bansal et al., 2005). Ginger pure powder (Sigma), was suspended in $0.5 \%$ carboxymethylcellulose (CMC) in distilled water (vehicle). All other chemicals were of highest analytical grade available. All mandatory laboratory health and safety procedures have been complied with in the course of conducting the experimental work in this study.

\section{Experimental design and treatment protocol}

Animals were randomly allocated into four groups (10 rats each). Rats of the 1st group received $0.5 \% \mathrm{CMC}$ and intraperitoneal injections of saline and served as normal control group. Group 2 received a single necrogenic dose of DENA (200 mg/kg, i.p)(Tessitore et al., 1996) on day 21 of the study. Groups 3 and 4 received oral GE (108 or $216 \mathrm{mg} / \mathrm{kg} /$ day), respectively, for 28 days during which a single necrogenic dose of DENA ( $200 \mathrm{mg} / \mathrm{kg}$, i.p) on day 21 was injected. All animals were sacrificed $24 \mathrm{~h}$ after last GE treatment.

\section{Serum biochemical analysis}

Rats were anaesthetized with diethyl ether and blood samples were withdrawn from the retro-orbital venous plexus. Collected blood samples were allowed to stand for $10 \mathrm{~min}$ at room temperature then centrifuged at $4^{\circ} \mathrm{C}$ using cooling centrifuge (Laborezentrifugen, $2 \mathrm{k} 15$, Sigma, Germany) at 3,000 r.p.m for $10 \mathrm{~min}$. Sera were separated for assessment of levels of aspartate aminotransferase (AST) and alanine aminotransferase (ALT) using commercially available colorimetric assay kits (Biodiagnostic, Egypt) as previously described (Reitman and Frankel, 1957).

Hepatic, stomach and colon tissue biochemical analysis

Directly after blood sampling, rats were sacrificed by cervical dislocation under ether anesthesia. Liver, stomach and colon tissues were collected, washed in normal saline. The tissue was homogenized using MPW-120 homogenizer (Med instruments, Poland); the homogenate was centrifuged using a cooling centrifuge (Laborezentrifugen, 2k15, Sigma, Germany) at 4,000 r.p.m for $10 \mathrm{~min}$. and the supernatant was assessed for hepatic, stomach and colon levels of reduced glutathione (GSH) (Beutler et al., 1963), lipid peroxides as malondialdehyde (MDA) (Mihara and Uchiyama, 1978) and nitric oxide (NOx) metabolites (Miranda et al., 2001). Moreover, inflammatory markers such as interleukin- $1 \beta$ (IL-1 $\beta$ ) and tumor necrosis factor-alpha (TNF- $\alpha$ ) were assessed using ELISA kits (Hycult Biotech, Netherlands) and (RayBio, USA), respectively, according to the manufacturer's instructions. Finally, alpha-fetoprotein (AFP) and nuclear factor-erythroid 2-related factor 2 (Nrf 2) were assessed using ELISA kits (KAMIYA BIOMEDICAL, USA, Cat. No. KT-59172) and (CUSABIO, China, Cat. No CSB-EQ027869RA), respectively, according to the manufacturer's instructions.

Immunohistochemical analysis of cyclooxygenase-2 (COX-2)

For immunohistochemistry, $4 \mu \mathrm{m}$ thick deparaffinized liver tissue sections were used. Briefly, deparaffinized liver slices were incubated overnight with the antibodies against COX-2 diluted 1:100, Endogenous peroxidase activity was blocked by incubation in $0.075 \%$ hydrogen peroxide in PBS. For antibody detection DAKO EnVision+ System, Peroxidase/DAB kit was employed. The sections were then counterstained with hematoxylin, dehydrated using graded alcohols and xylene, and mounted with Entelan. The immunostaining intensity and cellular localization of COX-2 was analyzed by light microscopy.

\section{Histopathological examination}

The other parts of liver tissues were fixed in $10 \%$ 
neutral buffered formalin and embedded in paraffin wax. Sections of $4 \mu \mathrm{m}$ thick were stained with Hematoxylin and Eosin ( $\mathrm{H}$ and $\mathrm{E})$ and examined using binocular Olympus CX31 microscope (Bancroft et al., 1996).

\section{Statistical analysis}

All values are presented as means \pm standard error of the means (SEM) of eight experiments. Comparisons between different groups were carried out using one way analysis of variance (ANOVA) followed by Tukey's multiple comparison post hoc test. Difference was considered significant when $\mathrm{p}<0.05$. GraphPad prism $^{\circledR}$ software version 6 for Windows (USA) was used to carry out these statistical tests.

\section{Results}

Effect of ginger extract on liver function enzymes

Administration of single intraperitoneal dose of DENA $(200 \mathrm{mg} / \mathrm{kg})$ resulted in a significant elevation of liver

Table 1. Effect of Ginger Extract on Interleukin 1-Beta (IL-1 $\beta$ ) Level in Liver, Stomach and Colon of DENATreated Rats

\begin{tabular}{lccc}
\hline & \multicolumn{2}{c}{ IL-1beta (IL-1 $\beta, \mathrm{pg} / \mathrm{ml})$} & \\
& Liver & Stomach & Colon \\
\hline Normal & $316.5^{\mathrm{b}}+22.7$ & $144.2^{\mathrm{b}}+5.7$ & $184.6^{\mathrm{b}}+15.47$ \\
DENA & $552.2^{\mathrm{a}}+18.8$ & $442.6^{\mathrm{a}}+39.7$ & $416.0^{\mathrm{a}}+20.36$ \\
$\begin{array}{l}\text { DENA-Ginger } \\
(108 \mathrm{mg} / \mathrm{kg})\end{array}$ & $390.2^{\mathrm{a}, \mathrm{b}}+3.7$ & $249.8^{\mathrm{a}, \mathrm{b}}+18.1$ & $269.0^{\mathrm{a}, \mathrm{b}}+11.46$ \\
$\begin{array}{l}\text { DENA-Ginger } \\
(216 \mathrm{mg} / \mathrm{kg})\end{array}$ & $364.9^{\mathrm{b}}+12.0$ & $295.7^{\mathrm{a}, \mathrm{b}}+11.4$ & $228.6^{\mathrm{b}}+16.11$ \\
\hline
\end{tabular}

Control, rats treated with the vehicle and represented the normal group; DENA, rats treated with diethyl nitrosamine; DENA-Ginger $(108 \mathrm{mg} / \mathrm{kg})$, rats treated with diethyl nitrosamine and ginger (108 $\mathrm{mg} / \mathrm{kg} /$ day); DENA-Ginger $(216 \mathrm{mg} / \mathrm{kg})$, rats treated with diethyl nitrosamine and ginger $(216 \mathrm{mg} / \mathrm{kg} / \mathrm{day})$. Each value represents the mean \pm S.E.M ( $n=6)$. Statistical analysis was carried out using one-way ANOVA test followed by Tukey post hoc test. ${ }^{\text {a }}$ Significantly different from normal group at $\mathrm{p}<0.05$. ${ }^{\mathrm{b}}$ Significantly different from DENA group at $\mathrm{p}<0.05 .{ }^{\mathrm{c}}$ Significantly different from the other DENA-Ginger group at $\mathrm{p}<0.05$

Table 2. Effect of Ginger Extract on Tumor Necrosis Factor-Alpha (TNF- $\alpha$ ) Level in Liver, Stomach and Colon of DENA-Treated Rats

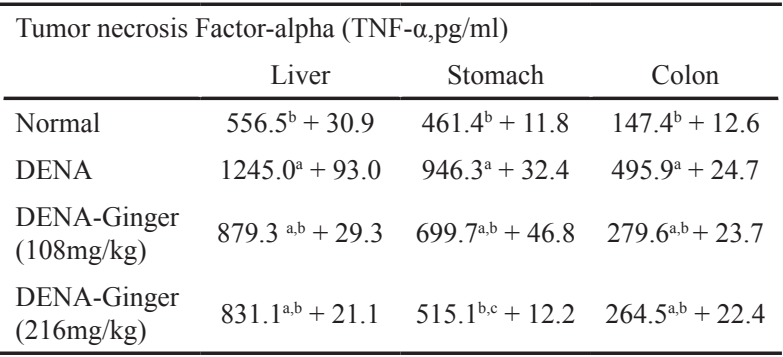

Control, rats treated with the vehicle and represented the normal group; DENA, rats treated with diethyl nitrosamine; DENA-Ginger $(108 \mathrm{mg} / \mathrm{kg})$, rats treated with diethyl nitrosamine and ginger (108 $\mathrm{mg} / \mathrm{kg} /$ day); DENA-Ginger (216 $\mathrm{mg} / \mathrm{kg})$, rats treated with diethyl nitrosamine and ginger $(216 \mathrm{mg} / \mathrm{kg} / \mathrm{day})$. Each value represents the mean \pm S.E.M $(n=6)$.Statistical analysis was carried out using one-way ANOVA test followed by Tukey post hoc test. ${ }^{a}$ Significantly different from normal group at $\mathrm{p}<0.05$. ${ }^{\mathrm{b}}$ Significantly different from DENA group at $\mathrm{p}<0.05$. ${ }^{\mathrm{c}}$ Significantly different from the other DENA-Ginger group at $\mathrm{p}<0.05$.
Table 3. Effect of Ginger Extract on Alpha-Fetoprotein (AFP) Level in Liver, Stomach and Colon of DENATreated Rats

\begin{tabular}{lccc}
\hline \multicolumn{4}{c}{ Alpha-fetoprotein (AFP, ng/g tissue) } \\
& Liver & Stomach & Colon \\
\hline Control & $13.30^{\mathrm{b}} \pm 0.49$ & $2.00^{\mathrm{b}} \pm 0.13$ & $3.59^{\mathrm{b}} \pm 0.20$ \\
DENA & $154.57^{\mathrm{a}} \pm 5.26$ & $11.61^{\mathrm{a}} \pm 0.60$ & $29.45^{\mathrm{a}} \pm 1.92$ \\
$\begin{array}{l}\text { DENA-Ginger } \\
(108 \mathrm{mg} / \mathrm{kg})\end{array}$ & $70.14^{\mathrm{a}, \mathrm{b}} \pm 1.89$ & $6.22^{\mathrm{a}, \mathrm{b}} \pm 0.21$ & $10.28^{\mathrm{a}, \mathrm{b}} \pm 0.42$ \\
$\begin{array}{l}\text { DENA-Ginger } \\
(216 \mathrm{mg} / \mathrm{kg})\end{array}$ & $49.67^{\mathrm{a}, \mathrm{b}, \mathrm{c}} \pm 1.58$ & $3.72^{\mathrm{a}, \mathrm{b}, \mathrm{c}} \pm 0.21$ & $6.78^{\mathrm{b}} \pm 0.21$ \\
\hline
\end{tabular}

Control, rats treated with the vehicle and represented the normal group; DENA, rats treated with diethyl nitrosamine; DENA-Ginger $(108 \mathrm{mg}$ / $\mathrm{kg})$, rats treated with diethyl nitrosamine and ginger $(108 \mathrm{mg} / \mathrm{kg} / \mathrm{day})$; DENA-Ginger $(216 \mathrm{mg} / \mathrm{kg})$, rats treated with diethyl nitrosamine and ginger $(216 \mathrm{mg} / \mathrm{kg} / \mathrm{day})$. Each value represents the mean \pm S.E.M $(n=6)$.Statistical analysis was carried out using one-way ANOVA test followed by Tukey post hoc test. ${ }^{\text {a }}$ Significantly different from normal group at $\mathrm{p}<0.05$. ${ }^{\mathrm{b}}$ Significantly different from DENA group at $\mathrm{p}<0.05$. ${ }^{\mathrm{c}}$ Significantly different from the other DENA-Ginger group at $\mathrm{p}<0.05$.

function biomarkers. Liver function enzymes, AST and ALT, were elevated significantly in DENA-treated rats compared to their normal counterparts. Pre-treatment of rats with ginger extract at $108 \mathrm{mg} / \mathrm{kg} /$ day, showed insignificant effect on either AST or ALT serum levels. While Pre-treatment of rats with ginger extract at 216 $\mathrm{mg} / \mathrm{kg} /$ day, showed significant reduction in AST level reporting normal levels of AST in DENA- treated rats with insignificant effect on ALT serum levels (Figure 1).

Effect of ginger extract on liver, stomach, and colon tissues oxidative stress parameters

The GSH content in liver, stomach, and colon was significantly reduced following DENA administration in rats. Treatment of rats with ginger restored the normal GSH content in the liver and colon. However, normal level of stomach GSH was only observed in the group treated with the lower dose of ginger; in the rats treated with the high dose, the stomach GSH content was significantly lower than the normal and non-significantly different from that

Table 4. Effect of Ginger Extract on Nuclear FactorErythroid 2-Related Factor 2 (Nrf2) Level in Liver, Stomach and Colon of DENA-Treated Rats

\begin{tabular}{lccc}
\multicolumn{4}{c}{ Nuclear factor-erythroid 2-related factor 2 (Nrf2, pg/g tissue) } \\
& Liver & Stomach & Colon \\
\hline Control & $29.37^{\mathrm{b}} \pm 1.29$ & $7.99^{\mathrm{b}} \pm 0.32$ & $18.92^{\mathrm{b}} \pm 0.37$ \\
DENA & $6.52^{\mathrm{a}} \pm 0.34$ & $1.33^{\mathrm{a}} \pm 0.05$ & $3.5^{\mathrm{a}} \pm 0.14$ \\
$\begin{array}{l}\text { DENA-Ginger } \\
(108 \mathrm{mg} / \mathrm{kg})\end{array}$ & $13.98^{\mathrm{a}, \mathrm{b}} \pm 0.39$ & $3.19^{\mathrm{a}, \mathrm{b}} \pm 0.20$ & $9.25^{\mathrm{a}, \mathrm{b}} \pm 0.26$ \\
$\begin{array}{l}\text { DENA-Ginger } \\
(216 \mathrm{mg} / \mathrm{kg})\end{array}$ & $20.13^{\mathrm{a}, \mathrm{b}, \mathrm{c}} \pm 0.46$ & $4.52^{\mathrm{a}, \mathrm{b}, \mathrm{c}} \pm 0.21$ & $11.98^{\mathrm{a}, \mathrm{b}, \mathrm{c}} \pm 0.36$ \\
\hline
\end{tabular}

Control, rats treated with the vehicle and represented the normal group; DENA, rats treated with diethyl nitrosamine; DENA-Ginger $(108 \mathrm{mg}$ / $\mathrm{kg})$, rats treated with diethyl nitrosamine and ginger $(108 \mathrm{mg} / \mathrm{kg} / \mathrm{day})$; DENA-Ginger $(216 \mathrm{mg} / \mathrm{kg})$, rats treated with diethyl nitrosamine and ginger $(216 \mathrm{mg} / \mathrm{kg} /$ day $)$. Each value represents the mean \pm S.E.M $(n=6)$.Statistical analysis was carried out using one-way ANOVA test followed by Tukey post hoc test. ${ }^{a}$ Significantly different from normal group at $\mathrm{p}<0.05$. ${ }^{\mathrm{b}}$ Significantly different from DENA group at $\mathrm{p}<0.05$. ${ }^{\mathrm{c}}$ Significantly different from the other DENA-Ginger group at $\mathrm{p}<0.05$. 


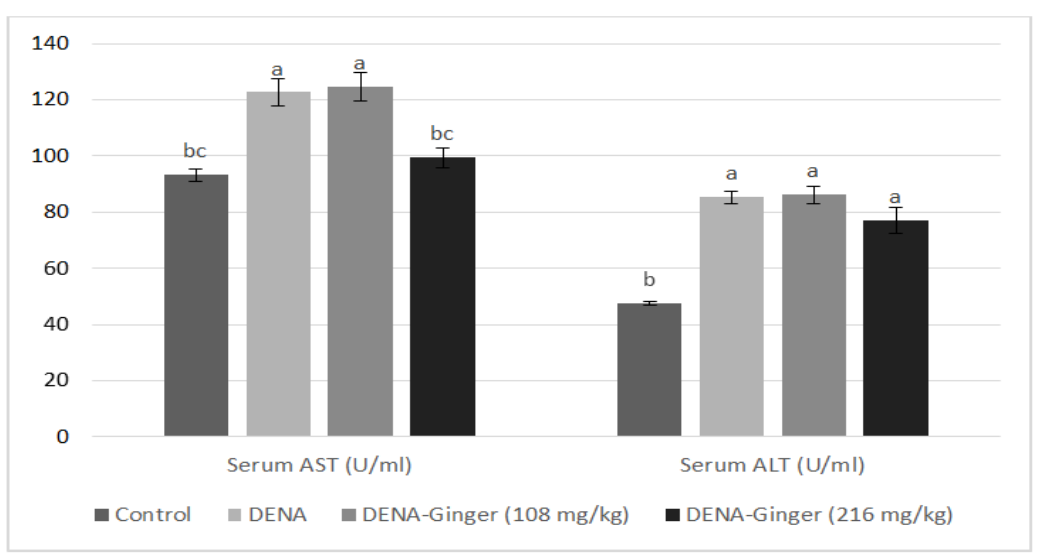

Figure 1. Effect of Ginger Extract on Liver Function Enzymes of DENA-Treated Rats. Control, rats treated with the vehicle and represented the normal group; DENA, rats treated with diethyl nitrosamine; DENA-Ginger (108 mg/ $\mathrm{kg})$, rats treated with diethyl nitrosamine and ginger $(108 \mathrm{mg} / \mathrm{kg} /$ day $)$; DENA-Ginger $(216 \mathrm{mg} / \mathrm{kg})$, rats treated with diethyl nitrosamine and ginger $(216 \mathrm{mg} / \mathrm{kg} /$ day $)$. a Significantly different from normal group at $\mathrm{p}<0.05$; b Significantly different from DENA group at $\mathrm{p}<0.05$; c Significantly different from the other DENA-Ginger group at $\mathrm{p}<0.05$.
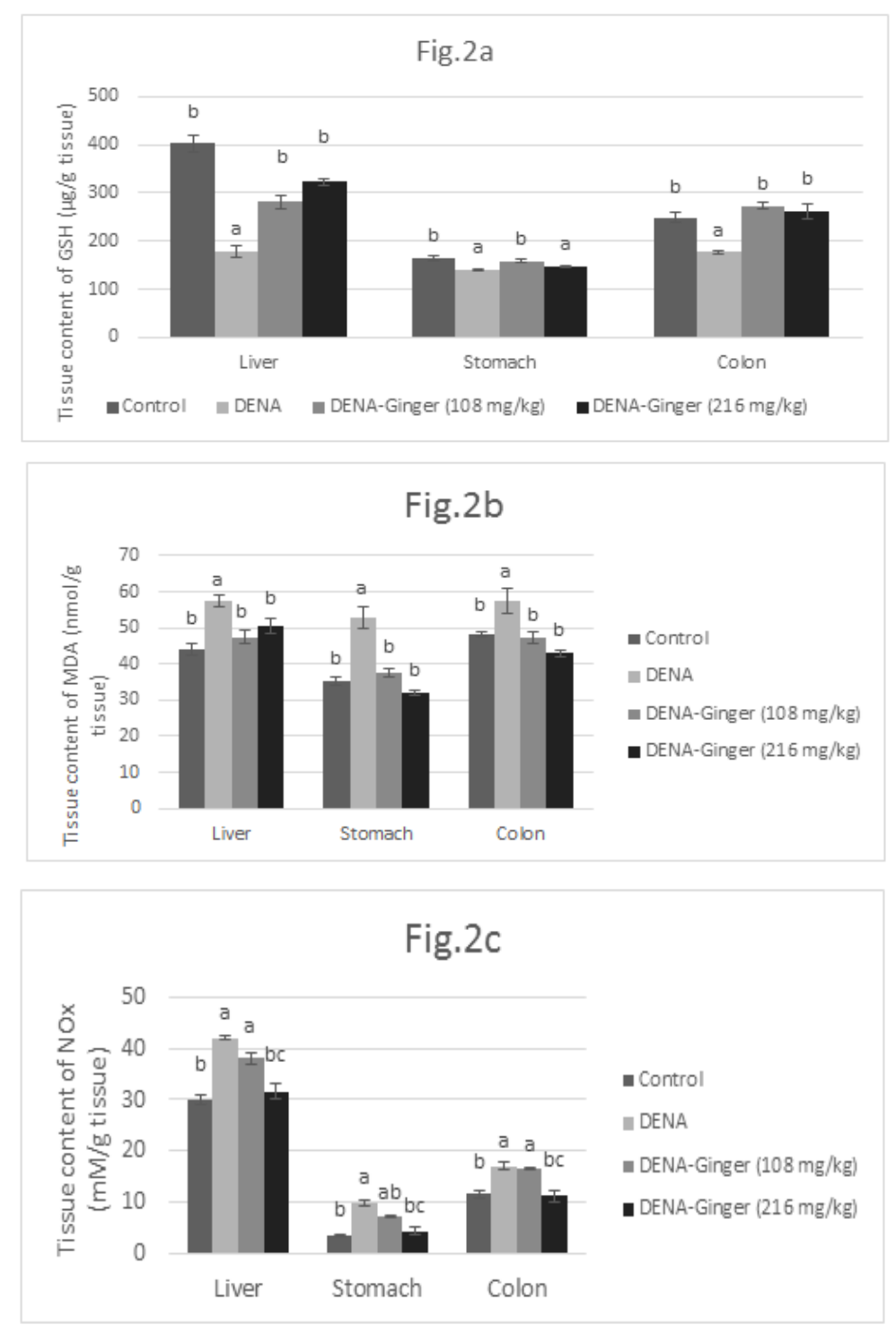

Figure 2. Effect of Ginger Extract Liver, Stomach and Colon contents of GSH (a), MDA (b), and NOx(c) of DENAtreated Rats. Control, rats treated with the vehicle and represented the normal group; DENA, rats treated with diethyl nitrosamine; DENA-Ginger (108 mg/kg), rats treated with diethyl nitrosamine and ginger (108 mg/kg/day); DENAGinger $(216 \mathrm{mg} / \mathrm{kg})$, rats treated with diethyl nitrosamine and ginger $(216 \mathrm{mg} / \mathrm{kg} /$ day $)$. a Significantly different from normal group at $\mathrm{p}<0.05$; b Significantly different from DENA group at $\mathrm{p}<0.05$; c Significantly different from the other DENA-Ginger group at $\mathrm{p}<0.05$. 


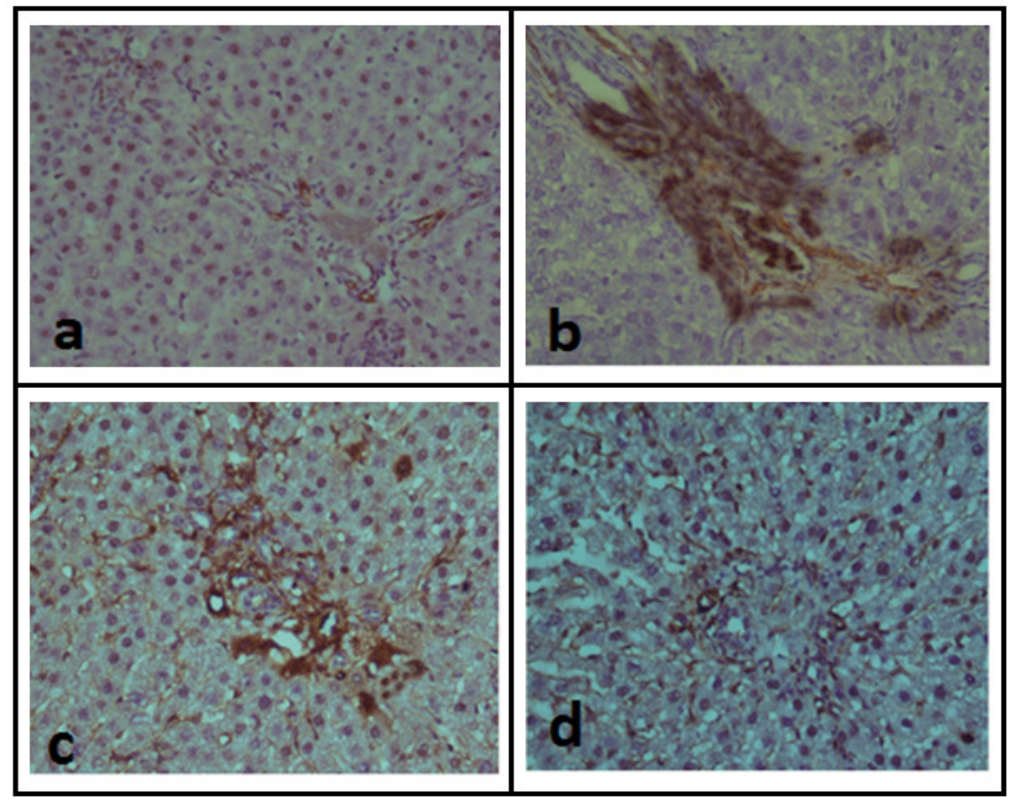

Figure 3. Effect of GE on COX2 Immunoreactivity in Hepatic Tissues in DENA-Induced Injury. (a) Control group: showed no positive inflammatory foci and negative COX2 immunoreactivity. (b) DENA group: showed strong positive stain in the area of inflammation exhibited sever COX2 immunoreactivity. (c) GE (108 mg/ $/ \mathrm{kg}$ ) group: moderate immunoreactivity. (d) GE (216 mg/kg) group: mild COX2 immunoreactivity. (COX2, x400)

of DENA-treated group. On the other hand, a significant elevation of the liver, stomach, and colon MDA content was detected following DENA administration. Treatment of rats with the both doses of ginger significantly retrieved the altered level of MDA in those organs' tissues.

Moreover, a significant increase in liver, stomach, and colon content of NOx was observed in rats treated with DENA. Treatment of rats with the higher dose of ginger has been found to restore the normal levels of NOx and its effect was significantly better than that of the lower dose (Figure $2 \mathrm{a}, \mathrm{b}$, and c).

Effect of ginger extract on liver, stomach, and colon tissues pro-inflammatory cytokines; interleukin-1

Liver, stomach, and colon content of the pro-inflammatory cytokine IL- $1 \beta$ was significantly reduced by DENA administration in rats. Treatment of rats with ginger significantly reduced IL- $1 \beta$ content in
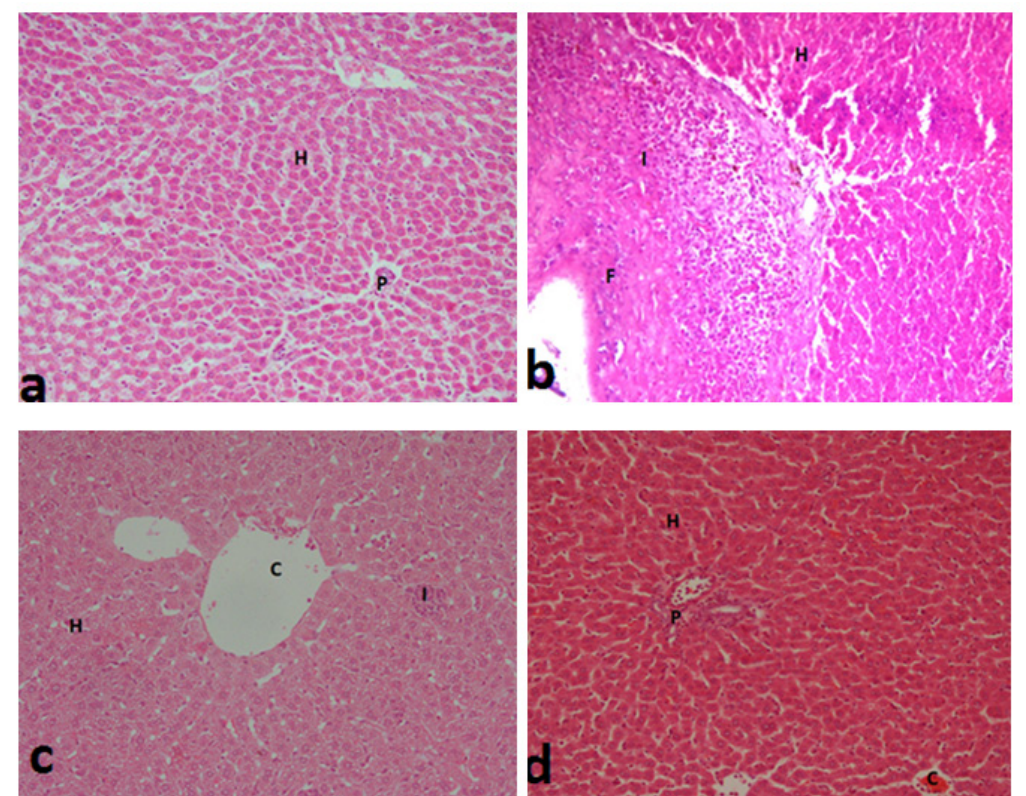

Figure 4. Effect of GE on the Histopathological Changes in the Hepatic Tissue in DENA-Induced Injury. (a) Normal control: showed normal architecture with the hepatocytes are normal run in thin plates $(\mathrm{H})$, the portal areas showed normal structures with no fibrosis or inflammation (P). (b) DENA group: dense inflammatory cell infiltrate (I), areas of fibrosis $(\mathrm{F})$, the hepatocytes are degenerated $(\mathrm{H})$. (c) GE $(108 \mathrm{mg} / \mathrm{kg})$ group: degeneration of some of the hepatocytes $(\mathrm{H})$, the cytoplasm appear foamy. Few foci of inflammation are still seen (I), some vessels are still dilated (C). (D) GE $(216 \mathrm{mg} / \mathrm{kg})$ group; showed better cytomorphology of the hepatocytes $(\mathrm{H})$; with almost normal appearance of their cytoplasm. No foci of inflammation. No portal inflammation (P). The blood vessels showed mild dilatation and congestion (C ). (H\&E) (a and d x200; b and cx400). 
the liver, stomach and colon by the two applicable doses. While the high dose of ginger significantly reduced both liver and colon IL-1 $\beta$ with no significant difference from normal group (Table 1). In addition, DENA administration significantly increased liver, stomach, and colon content of TNF- $\alpha$, while pretreatment with ginger extract for four weeks significantly reduced TNF- $\alpha$ compared to DENA-treated rats. Ginger extract, at $216 \mathrm{mg} / \mathrm{kg}$, significantly reduced TNF- $\alpha$ in stomach of DENA-treated animals compared to the other dose of ginger (108mg/ kg) (Table 2).

Effect of ginger extract on liver, stomach and colon tissues alpha-fetoprotein (AFP)

Alpha-fetoprotein (AFP) was significantly increased after DENA single intraperitoneal injection in liver, stomach and colon of rats compared to normal rats. Pretreatment with ginger extract significantly inhibited the dramatic elevation in AFP after DENA injection in liver, stomach and colon. Moreover, ginger extract at, 216 $\mathrm{mg} / \mathrm{kg}$, exerted significant reduction in AFP compared to the other dose of the extract in both liver and stomach, while restored normal levels of AFP in the colon of DENA-treated rats (Table 3).

Effect of ginger extract on liver, stomach and colon nuclear factor-erythroid 2-related factor 2 (Nrf2)

Diethylnitrosamine (DENA) in a single intraperitoneal injection $(200 \mathrm{mg} / \mathrm{kg})$ significantly decreased nuclear factor-erythroid 2-related factor-2 (Nrf-2) in liver, stomach and colon of rats compared to normal rats. Pretreatment with ginger extract significantly inhibited the reduction in Nrf-2 level of liver, stomach and colon compared DENA group. Moreover, ginger extract, at $216 \mathrm{mg} / \mathrm{kg}$, exerted significant elevation in Nrf-2 level of liver, stomach and colon tissues compared to the other dose of the extract (Table 4).

\section{Immunohistochemical and histopathological assessment} of hepatic tissues

Immunohistochemical assessment of hepatic cyclooxygenase-2 (COX2) revealed strong immunoreactivity of COX2 in hepatic tissues on week after $200 \mathrm{mg} / \mathrm{kg}$ of DENA intraperitoneal injection. Meanwhile, administration of GE at $108 \mathrm{mg} / \mathrm{kg}$ showed moderate COX2 immunoreactivity compared to GE at 216 which displayed mild COX2 immunoreactivity (Figure 3).

Histopathological examination of liver tissues revealed dense inflammatory cell infiltrate areas of fibrosis and degeneration of hepatocytes after DENA injection. GE $(108 \mathrm{mg} / \mathrm{kg})$ exerted slight improvement while degeneration of some of the hepatocytes, foamy cytoplasm and inflammation are still seen. GE (216 mg/ $\mathrm{kg}$ ) showed better cytomorphology of the hepatocytes with almost normal appearance of their cytoplasm, no foci of inflammation, No portal inflammation, and blood vessels showed mild dilatation and congestion with significant improvement in the overall hepatic histopathological picture (Figure 4).

\section{Discussion}

Being one of the most frequently and heavily consumed natural dietary component, ginger and its polyphenolic compounds; zingerone, [6]-gingerol, and shogaol; have been reported for their chemoprotective and antioxidant effects in carcinogenesis (Chung et al., 2001; Mohd-Yusof et al., 2002; Manju and Nalini, 2005). Having more profound effect than gingerols, its active components, (Mukkavilli et al., 2014); researchers highlight the importance of utilizing entire ginger extract over its active components (Prasad and Tyagi, 2015b) with recently reported anti-oxidant, anti-inflammatory and anti-apoptotic effects of whole ginger rhizome extract in rat model of diabetic nephropathy (Al Hroob et al., 2018)

Nitrosamines as dietary carcinogens are associated with the etiology of HCC and contribute to the development of oxidative stress, chronic inflammation, and cellular proliferation in response to tissue injury, leading to hepatocarcinogenesis (Darvesh and Bishayee, 2013).

Both environmental and N-nitrosamines born-food hold a health hazard for human and animals. Experimentally, DENA is used to investigate its cytotoxic mechanisms on different tissues and organs. Moreover, DENA causes alterations in serum and tissue enzyme markers (Atakisi et al., 2013). The International Agency for Research on Cancer (IARC) categorized DENA as a "probable carcinogenic to humans" (category A2) (IARC, 1987). The catalysis of DENA by cytochrome P-450-dependent enzymes of monooxygenase system yields active metabolite ethyl radical that covalently binds to DNA leading to cellular necrosis, mutation and cancer (Skog, 2002). Oxidative stress-induced cell injury plays a crucial role in DENA-induced carcinogenesis (Bansal et al., 2000).

Liver-specific enzyme markers, including aspartate aminotransferase (AST), alanine aminotransferase (ALT), alkaline phosphatase (ALP) and $\gamma$-glutamyltransferase (GGT), are released during hepatocytes' injury (Galle et al., 2014). AST, ALT and ALP are considered more sensitive parameters to assess liver injury in rodent species (Galle et al., 2014). Previous studies indicated that DENA-induced liver injury is accompanied by elevated activities of these enzymes (Sadik et al., 2008; Sayed-Ahmed et al., 2010; Jin et al., 2013; Galle et al., 2014). In accordance with present data that clearly stated a significant elevation in ALT and AST enzyme activities after a single necrogenic dose of DENA, indicating established liver injury. Taking into consideration the hepatoprotective activity of ginger extract (GE) against several hepatotoxic agents (Atta et al., 2010; Abdel-Azeem et al., 2013; Shivashankara et al., 2013; Vasquez-Garzon et al., 2013), ginger treatment significantly ameliorated the elevation in AST at high dose level while no significant reduction in ALT activity was reported.

Oxidative stress and nitrosative stress, through generation of reactive oxygen species (ROS) and reactive nitrogenous species, act as an important influencing factor to carcinogenesis and both are substantial key factors in cancer as an end-stage of chronic diseases (Kawanishi et al., 2006). Current results demonstrated significant 
decrease in GSH with increased levels of MDA and total nitrate/nitrite (NOx) in liver, stomach and colon of DENA-treated rats. DENA, in a single necrogenic dose $(200 \mathrm{mg} / \mathrm{kg})$, produced significant increase in hepatic thiobarbituric acid reactive substances (TBARs) and total nitrate/nitrite (NOx) and decreased reduced glutathione $(\mathrm{GSH})$, glutathione peroxidase (GPx), glutathione-s-transferase (GsT) and catalase (CAT) activity (Gayathri et al., 2009; Sayed-Ahmed et al., 2010; Atakisi et al., 2013). Ginger attenuated the perturbation in oxidative stress markers as evidenced by increase in liver, stomach and colon reduced GSH, and alleviation of MDA and NOx levels in DENA-treated rats. The antioxidant activities of ginger in liver (Yusof et al., 2008), stomach (al-Yahya et al., 1989; Yoshikawa et al., 1994; Nanjundaiah et al., 2011) and colon (Manju and Nalini, 2005) have been well-established. Nevertheless, modulation of oxidative damage and subsequently inflammation is considered to be of advantage for cancer prevention (Bishayee et al., 2010). On the other hand, DNA- oxidative and nitrosative damage occurs at the sites of carcinogenesis is a potential risk of inflammation-mediated carcinogenesis in humans and animal models, regardless of etiology (Kawanishi et al., 2006; Laothong et al., 2010). As a consequence of DENA-induced oxidative and nitrosative DNA damage (Klaunig and Kamendulis, 2004; Unsal and Belge-Kurutas, 2017), inflammatory markers such as interleukin-1 beta (IL-1 $\beta$ ) and tumor necrosis factor alpha (TNF- $\alpha$ ) are significantly elevated in DENA-treated liver, stomach and colon, in the present study. Further, the release of pro-inflammatory cytokines and chemokines (IL-6, IL-8, IL-1 $\beta$, TNF- $\alpha$, CCL2, CCL20) as a result of macrophages and neutrophils activation, is thought to play an important role in the pathogenesis of cancer in human liver (Uehara et al., 2014). Others reported a mixed inflammatory cell infiltration (lymphocytes, neutrophils, eosinophils, and Kupffer cells) by DENA administration (Duan et al., 2014; Ding et al., 2017).

Ginger pretreatment exerted a significant anti-inflammatory effect on DENA-treated liver, stomach and colon contents of IL- $1 \beta$ and TNF- $\alpha$, in a dose dependent pattern. Ginger extract $(100 \mathrm{mg} / \mathrm{kg})$ acts as an anti-cancerous and anti-inflammatory agent by abrogating the activation of NFKB via the suppression of pro-inflammatory cytokine, TNF- $\alpha$ (Hudson et al., 2006; Habib et al., 2008). The active components of ginger, 6-gingerol and 6-paradol, possess a strong antiinflammatory activity through suppression of TNF- $\alpha$ production in TPA-treated female ICR-mice and rats (Park et al., 1998; Surh, 2003).

On the other hand, being overexpressed in many types of malignant tumors, cycloxygenase- 2 (COX-2) is one of the inflammatory mediators associated with carcinogenesis in colorectal, prostate, breast and hepatocellular cancers. Its frequent aberrant expression has been observed in human and animal HCCs. Purportedly, COX-2 expression increased in well-differentiated HCCs than normal or less differentiated HCCs suggesting its involvement in early stages of hepatocarcinogenesis (Cui et al., 2005; Wu, 2006; Giannitrapani et al., 2009). Obviously, DENA induced COX-2 over-expression as evidenced by immunohistochemical study of rat liver after single intraperitoneal dose of DENA. Nevertheless, an evident cross-talk between $\mathrm{NO}$ and $\mathrm{COX}-2$ expression in cancer cells is reported where $\mathrm{NO}$ donor induced COX-1 and COX-2 expression in colon cancer cell lines in a dose and time dependent fashion (Liu et al., 2003) with correlation between iNOS expression and COX-2 overexpression in enhanced tumor growth, angiogenesis and inflammation in various tumors (Rahman et al., 2001; Ohta et al., 2006). Similarly, a well-established association between NO, inflammatory mediators; MPO, IL-1 $\beta$ and COX-2 overexpression was reported in other models of hepatic and renal injuries (Mansour et al., 2017a; Mansour et al., 2017b).

Animal models of liver cancer have shown that non-steroidal anti-inflammatory drugs (NSAIDs) exert chemopreventive and therapeutic effects (Cervello and Montalto, 2006), with significant reduction in tumor size (Galant et al., 2013). Hence, the utilization of natural agents with an anti-inflammatory activity is noteworthy. Ginger extract pretreatment showed lower COX-2 immunohistochemical staining in DENA-treated liver tissues in a dose dependent manner. The observation is in accordance with other studies reported potent antiinflammatory effect of ginger preparations and isolated compounds via inhibition of COX-2 (Tjendraputra et al., 2001; Rani et al., 2011), nuclear factor $\kappa$ B (Grzanna et al., 2005), along with three fold inhibition of COX-2 more than COX-1 (van Breemen et al., 2011).

Alpha-fetoprotein (AFP) is a well-known tumor marker indicator of HCC (Sell et al., 1983). Being a growth regulatory cell-signaling factor, it has been reported to promote cell proliferation, suppress apoptosis, and act as an immunosuppressive agent (Mizejewski, 2013). More than $70 \%$ of HCC patients displayed high serum concentration of AFP, therefore, AFP is strongly suggestive of HCC (Endo et al., 1975). Moreover, elevated serum levels of AFP indicates the growth of malignant lung and bladder tumors as well as gastrointestinal cancers of stomach, pancreas, and colon (Mizejewski, 2014). High mortality and morbidity rates were reported to patients with AFP-positive-gastrointestinal cancer $(\mathrm{AFP}(+) \mathrm{GC})$ than AFP(-)GC-patients due to active cell proliferation, high mitotic rate, amplified cell invasion and migration, rapid tumor progression and advanced tumor stage ( $\mathrm{He}$ et al., 2016).

Elevated serum levels of AFP have been detected in animals bearing liver tumors after treatment with certain hepatocarcinogens including DENA (Kroes et al., 1975). The increased level of AFP observed in DENA-induced animals is indicative of HCC (Jagan et al., 2008). In the present study, DENA induced significant elevation of AFP in liver, stomach and colon by 92,82 and $86 \%$, respectively, compared to normal groups. DENA-induced elevation in AFP was reported earlier (Das et al., 2016).

It was observed that stimulation of the nuclear oncogenes (c-fos, c-jun, c-myc) and the two gene transcripts of the AFP gene are triggered after 4-12 hrs and after 4-24 hrs, respectively, following turpentine-induced acute inflammation in the rat (Koj et al., 1983). Addition of AFP to skin cultures of human keratinocytes with 
T-lymphocytes resulted in boosted baseline expression of cytokines, chemokines, and growth factors (Potapovich et al., 2009). AFP exhibits a vital role in the regulation of tumor growth, cell differentiation and proliferation of human hepatoma cells through the AFP receptors ( $\mathrm{Li}$ et al., 2002). Accordingly, elevated levels of inflammatory cytokines and NOx along with AFP, following DENA administration, support the notion that AFP serves as both an acute and a chronic phase reactant depending on its stage of ontogeny (Mizejewski, 2015). The majority of AFP-producing cancers originate from the stomach, bile duct, and pancreas. Clinically, eleven cases of colorectal cancer with only one case with early rectal cancer have been diagnosed as an AFP-producing tumor by immunohistochemistry (Anzai et al., 2015). Hepatic, gastric and colonic contents of AFP were markedly decreased by ginger extract pretreatment by approximately $50 \%$ compared to DENA group in a dose dependent manner. The chemopreventive activity of ginger extract and its constituents has been reported previously against myriad models of liver cancer (Mansour et al., 2010; Taha et al., 2010), gastric cancer rat models (Ko and Leung, 2010; Prasad and Tyagi, 2015b) and experimental colon carcinogenesis (Yoshimi et al., 1992; Manju and Nalini, 2006). Clinically, two grams daily of ginger supplement, to patients with increased risk for colorectal cancer, reduce proliferation in the crypts of normal-appearing colorectal epithelium and increase apoptosis and differentiation relative to proliferation (Citronberg et al., 2013).

The redox-sensitive transcription factor, nuclear factor-erythroid 2-related factor 2 (Nrf2), plays a central role in the inducible expression of genes encoding detoxifying systems, including phase II drug-metabolizing enzymes; NADPH, NAD(P)H quinone oxidoreductase 1 , glutathione peroxidase, ferritin, heme oxygenase-1 (HO-1) (Jaiswal, 2004). These defense enzymes are coordinately induced through the antioxidant responsive element (ARE) and are tightly regulated by Nrf2 (Nguyen et al., 2003). The attenuated expression of these enzymes in Nrf2-deficient mice has verified the role of Nrf2 in the regulation of many detoxifying and antioxidant enzymes under oxidative stress conditions; rendering Nrf2-deficient mice more vulnerable to carcinogen-induced toxicity and carcinogenesis (Enomoto et al., 2001; Ramos-Gomez et al., 2001). Diethylnitrosamine administration significantly decreased hepatic, gastric and colonic Nrf2 by 78,83 and $82 \%$, respectively, after 7 days of administration. This result was reflected by the dramatic decrease in reduced GSH content of the investigated tissues besides the increase in oxidative stress marker (MDA) and inflammatory markers (IL- $1 \beta$ and TNF- $\alpha$ ). Similarly, a recent study reported that DENA down-regulates Nrf2 in the liver along with induction of oxidative stress, inflammation and angiogenesis (Mahmoud et al., 2017). Both doses of ginger extract protected liver, stomach and colon from DENA-induced decrease in Nrf2 with significant difference between low and high dose of GE. Previous studies showed increased antioxidant enzymes including GSH, SOD, and GPx by GE (Jeena et al., 2013). Zerumbone, component of Asian ginger oil, elevates phase II detoxification enzymes as well as nuclear localization of Nrf2/ARE (Nakamura et al., 2004). The upregulation of Nrf2 by ginger extract could exert an anti-inflammatory effect through elevation of HO-1 expression leading to the inhibition of NFאB signaling (Chi et al., 2015) giving a new insight in cancer prevention through upregulation of Nrf2/ARE pathway by ginger consumption.

Ginger inhibits transcription factor $N F-\kappa B$, inflammatory cytokine TNF- $\alpha$ and targets several cellular molecules that contribute to tumorigenesis, cell survival, cell proliferation, invasion, and angiogenesis in different forms of GI cancers. Those molecular targets of ginger indicate that it may have the potential for preventing and treating GI cancer (Prasad and Tyagi, 2015b). Though the notion that Nrf2 inducers and/or Keap-1 suppressors may serve as promoters of cancer cell proliferation with increased resistance to ferroptosis cell death (Fan et al., 2017); ginger extract exerted an Nrf-2-inducing activity with concurrent inhibition of alpha-feto protein, proliferation marker, in all examined tissues and decline in oxidative and inflammatory markers, thus contributing to its chemoprevention activity probably via mechanism involving Nrf2/Keap1/ARE pathway. Therefore, further molecular investigation is warranted to outline ginger antioxidant/anti-inflammatory/anti-proliferative crosstalk mechanism.

Taking together current observation and previous supporting literature, GE supplementation ameliorated the distortion in liver architecture induced by DENA through hepatoprotective; antioxidative, anti-inflammatory, anti-proliferative and chemopreventive properties as evident by current histopathologic examination of liver tissues.

In conclusion, Ginger Extract alleviated DENA-induced decrease in reduced GSH, increase in MDA and NOx, elevations of IL- $1 \beta$, TNF- $\alpha$, and hepatic COX-2 expression, increase in AFP and decrease in Nrf2 of liver, stomach and colon of male Wistar albino rats via antioxidative, antiinflammatory, and eventually chemopreventive properties with proposed anti-proliferative effect by inhibition of AFP-producing tumor pathway.

\section{Acknowledgements}

This study was conducted in accordance with ethical rules for standard experimental animal studies and approved by the Medical Research Ethics Committee (MREC) of the National Research Centre under approval number: 15130 .

\section{Funding Statement}

The authors received no financial support for the research, authorship, and/or publication of this article.

\section{Conflict of Interests}

The authors declare none.

\section{References}

Abdel-Azeem AS, Hegazy AM, Ibrahim KS, et al (2013). Hepatoprotective, antioxidant, and ameliorative effects of ginger (Zingiber officinale Roscoe) and vitamin $\mathrm{E}$ in 
acetaminophen treated rats. J Diet Suppl, 10, 195-209.

Afzal M, Al-Hadidi D, Menon M, et al (2001). Ginger: an ethnomedical, chemical and pharmacological review. Drug Metabol Drug Interact, 18, 159-90.

al-Yahya MA, Rafatullah S, Mossa JS, et al (1989). Gastroprotective activity of ginger zingiber officinale rosc., in albino rats. Am J Chin Med, 17, 51-6.

Al Hroob AM, Abukhalil MH, Alghonmeen RD, et al (2018). Ginger alleviates hyperglycemia-induced oxidative stress, inflammation and apoptosis and protects rats against diabetic nephropathy. Biomed Pharmacother, 106, 381-9.

Anzai H, Kazama S, Kiyomatsu T, et al (2015). Alpha-fetoproteinproducing early rectal carcinoma: a rare case report and review. World J Surg Oncol, 13, 180.

Atakisi O, Atakisi E, Ozcan A, et al (2013). Protective effect of omega-3 fatty acids on diethylnitrosamine toxicity in rats. Eur Rev Med Pharmacol Sci, 17, 467-71.

Atta AH, Elkoly TA, Mouneir SM, et al (2010). Hepatoprotective effect of Methanol extracts of Zingiber officinale and Cichorium intybus. Indian J Pharm Sci, 72, 564-70.

Bancroft J, Stevens A, Turner D (1996). Theory and practice of histological techniques 4th Ed Churchill Living Stone, New York Edinburgh. Madrid, Sanfrancisco. Bansal A, Trivedi R, Soni G, et al (2000). Hepatic and renal oxidative stress in acute toxicity of $\mathrm{N}$-nitrosodiethylamine in rats. Indian $J$ Exp Biol, 38, 916-20.

Bansal AK, Bansal M, Soni G, et al (2005). Protective role of Vitamin E pre-treatment on N-nitrosodiethylamine induced oxidative stress in rat liver. Chem Biol Interact, 156, 101-11.

Bartsch H, Montesano R (1984). Relevance of nitrosamines to human cancer. Carcinogenesis, 5, 1381-93.

Beutler E, Duron O, Kelly BM (1963). Improved method for the determination of blood glutathione. J Lab Clin Med, 61, 882-8.

Binato M, Kruel Schmidt M, Silveira Volkweis B, et al (2008). Mouse model of diethylnitrosamine-induced gastric cancer. J Surg Res, 148, 152-7.

Bishayee A, Barnes KF, Bhatia D, et al (2010). Resveratrol suppresses oxidative stress and inflammatory response in diethylnitrosamine-initiated rat hepatocarcinogenesis. Cancer Prev Res (Phila), 3, 753-63.

Brown AC, Shah C, Liu J, et al (2009). Ginger's (Zingiber officinale Roscoe) inhibition of rat colonic adenocarcinoma cells proliferation and angiogenesis in vitro. Phytother Res, 23, 640-5

Cervello M, Montalto G (2006). Cyclooxygenases in hepatocellular carcinoma. World J Gastroenterol, 12, 5113-21.

Chi X, Yao W, Xia H, et al (2015). Elevation of HO-1 expression mitigates intestinal Ischemia-Reperfusion injury and restores tight junction function in a Rat liver transplantation model. Oxid Med Cell Longev, 2015, 986075.

Chung WY, Jung YJ, Surh YJ, et al (2001). Antioxidative and antitumor promoting effects of [6]-paradol and its homologs. Mutat Res, 496, 199-206.

Citronberg J, Bostick R, Ahearn T, et al (2013). Effects of ginger supplementation on cell-cycle biomarkers in the normal-appearing colonic mucosa of patients at increased risk for colorectal cancer: results from a pilot, randomized, and controlled trial. Cancer Prev Res (Phila), 6, 271-81.

Cui W, Yu CH, Hu KQ (2005). In vitro and in vivo effects and mechanisms of celecoxib-induced growth inhibition of human hepatocellular carcinoma cells. Clin Cancer Res, 11, 8213-21.

Darvesh AS, Bishayee A (2013). Chemopreventive and therapeutic potential of tea polyphenols in hepatocellular cancer. Nutr Cancer, 65, 329-44.
Das BK, Koti BC, Gadad PC (2016). Role of Lycopersicon esculentum in diethylnitrosamine-induced and phenobarbitalpromoted hepatocellular carcinoma. Indian J Health Sci Biomed Res, 9, 147.

Ding YF, Wu ZH, Wei YJ, et al (2017). Hepatic inflammationfibrosis-cancer axis in the rat hepatocellular carcinoma induced by diethylnitrosamine. J Cancer Res Clin Oncol, $143,821-34$

Duan XY, Pan Q, Yan SY, et al (2014). High-saturate-fat diet delays initiation of diethylnitrosamine-induced hepatocellular carcinoma. BMC Gastroenterol, 14, 195.

Endo Y, Kanai K, Oda T, et al (1975). Clinical significance of alpha-fetoprotein in hepatitis and liver cirrhosis. Ann NY Acad Sci, 259, 234-8.

Enomoto A, Itoh K, Nagayoshi E, et al (2001). High sensitivity of Nrf2 knockout mice to acetaminophen hepatotoxicity associated with decreased expression of ARE-regulated drug metabolizing enzymes and antioxidant genes. Toxicol Sci, 59, 169-77.

Fan Z, Wirth AK, Chen D, et al (2017). Nrf2-Keap1 pathway promotes cell proliferation and diminishes ferroptosis. Oncogenesis, 6, e371.

Galant LW, de Mattos AA, Menti E, et al (2013). The effect of celecoxib on the development of diethylnitrosamine-induced liver tumors in rats. Ann Hepatol, 12, 425-33.

Galle M, Crespo R, Rodenak Kladniew B, et al (2014). Suppression by geraniol of the growth of A549 human lung adenocarcinoma cells and inhibition of the mevalonate pathway in culture and in vivo: potential use in cancer chemotherapy. Nutr Cancer, 66, 888-95.

Gayathri R, Priya DK, Gunassekaran GR, et al (2009). Ursolic acid attenuates oxidative stress-mediated hepatocellular carcinoma induction by diethylnitrosamine in male Wistar rats. Asian Pac J Cancer Prev, 10, 933-8.

Giannitrapani L, Ingrao S, Soresi M, et al (2009). Cyclooxygenase-2 expression in chronic liver diseases and hepatocellular carcinoma. Ann N Y Acad Sci, 1155, 293-9.

Glauert HP, Calfee-Mason K, Stemm DN, et al (2010). Dietary antioxidants in the prevention of hepatocarcinogenesis: a review. Mol Nutr Food Res, 54, 875-96.

Grzanna R, Lindmark L, Frondoza CG (2005). Ginger--an herbal medicinal product with broad anti-inflammatory actions. J Med Food, 8, 125-32.

Habib SHM, Makpol S, Hamid NAA, et al (2008). Ginger extract (Zingiber officinale) has anti-cancer and anti-inflammatory effects on ethionine-induced hepatoma rats. Clinics, $\mathbf{6 3}$, $807-13$

He C, Fan X, Chen R, et al (2012). Osteopontin is involved in estrogen-mediated protection against diethylnitrosamineinduced liver injury in mice. Food Chem Toxicol, 50, 2878-85.

$\mathrm{He}$ L, YeF, Qu L, et al (2016). Protein profiling of alpha-fetoprotein producing gastric adenocarcinoma. Oncotarget, 7, 28448.

Hudson EA, Fox LH, Luckett JC, et al (2006). Ex vivo cancer chemoprevention research possibilities. Environ Toxicol Pharmacol, 21, 204-14.

IARC (1987). Overall evaluation of carcinogenicity: an updating of IARC Monographs Volumes 1-42. Lyon. IARC monographs on the evaluation of carcinogenic risks to humans.

Jagan S, Ramakrishnan G, Anandakumar P, et al (2008) Antiproliferative potential of gallic acid against diethylnitrosamine-induced rat hepatocellular carcinoma. Mol Cell Biochem, 319, 51-9.

Jaiswal AK (2004). Nrf2 signaling in coordinated activation of antioxidant gene expression. Free Radic Biol Med, 36, 1199-207. 
Janani P, Sivakumari K, Geetha A, et al (2010). Chemopreventive effect of bacoside A on N-nitrosodiethylamine-induced hepatocarcinogenesis in rats. J Cancer Res Clin Oncol, 136, 759-70.

Jayakumar S, Madankumar A, Asokkumar S, et al (2012). Potential preventive effect of carvacrol against diethylnitrosamine-induced hepatocellular carcinoma in rats. Mol Cell Biochem, 360, 51-60.

Jeena K, Liju VB, Kuttan R (2013). Antioxidant, anti-inflammatory and antinociceptive activities of essential oil from ginger. Indian J Physiol Pharmacol, 57, 51-62.

Jeong WS, Jun M, Kong AN (2006). Nrf2: a potential molecular target for cancer chemoprevention by natural compounds. Antioxid Redox Signal, 8, 99-106.

Jin X, Sun J, Miao X, et al (2013). Inhibitory effect of geraniol in combination with gemcitabine on proliferation of BXPC-3 human pancreatic cancer cells. J Int Med Res, 41, 993-1001.

Kang JS, Wanibuchi H, Morimura K, et al (2007). Role of CYP2E1 in diethylnitrosamine-induced hepatocarcinogenesis in vivo. Cancer Res, 67, 11141-6.

Kawanishi S, Hiraku Y, Pinlaor S, et al (2006). Oxidative and nitrative DNA damage in animals and patients with inflammatory diseases in relation to inflammation-related carcinogenesis. Biol Chem, 387, 365-72.

Kim SO, Kundu JK, Shin YK, et al (2005). [6]-Gingerol inhibits COX-2 expression by blocking the activation of $\mathrm{p} 38$ MAP kinase and NF-kappaB in phorbol ester-stimulated mouse skin. Oncogene, 24, 2558-67.

Klaunig JE, Kamendulis LM (2004). The role of oxidative stress in carcinogenesis. Annu Rev Pharmacol Toxicol, 44, 239-67.

Ko JK, Leung CC (2010). Ginger extract and polaprezinc exert gastroprotective actions by anti-oxidant and growth factor modulating effects in rats. J Gastroenterol Hepatol, 25, 1861-8.

Koj A, Dubin A, Kasperczyk H, et al (1983). Synthesis and secretion of some plasma proteins by tissue slices of Morris hepatoma 7,777 and liver from control and turpentineinjected rats. Folia Histochem Cytobiol, 21, 211-8.

Kroes R, Sontag JM, Sell S, et al (1975). Elevated concentrations of serum alpha-fetoprotein in rats with chemically induced liver tumors. Cancer Res, 35, 1214-7.

Laothong U, Pinlaor P, Hiraku Y, et al (2010). Protective effect of melatonin against Opisthorchis viverrini-induced oxidative and nitrosative DNA damage and liver injury in hamsters. $J$ Pineal Res, 49, 271-82.

Li MS, Li PF, Yang FY, et al (2002). The intracellular mechanism of alpha-fetoprotein promoting the proliferation of NIH $3 \mathrm{~T} 3$ cells. Cell Res, 12, 151-6.

Liu Q, Chan ST, Mahendran R (2003). Nitric oxide induces cyclooxygenase expression and inhibits cell growth in colon cancer cell lines. Carcinogenesis, 24, 637-42.

Mahmoud AM, Zaki AR, Hassan ME, et al (2017). Commiphora molmol resin attenuates diethylnitrosamine/phenobarbitalinduced hepatocarcinogenesis by modulating oxidative stress, inflammation, angiogenesis and Nrf2/ARE/HO-1 signaling. Chem Biol Interact, 270, 41-50.

Manju V, Nalini N (2005). Chemopreventive efficacy of ginger, a naturally occurring anticarcinogen during the initiation, post-initiation stages of 1,2 dimethylhydrazine-induced colon cancer. Clin Chim Acta, 358, 60-7.

Manju V, Nalini N (2006). Effect of ginger on bacterial enzymes in 1,2-dimethylhydrazine induced experimental colon carcinogenesis. Eur J Cancer Prev, 15, 377-83.

Mansour DF, Salama A, Hegazy RR, et al (2017a). Whey protein isolate protects against cyclophosphamide-induced acute liver and kidney damage in rats. J Appl Pharm Sci, 7, 111-20. Mansour DF, Saleh DO, Mostafa RE (2017b). Genistein
Ameliorates Cyclophosphamide - Induced Hepatotoxicity by modulation of oxidative stress and inflammatory mediators. Open Access Maced J Med Sci, 5, 836-43.

Mansour MA, Bekheet SA, Al-Rejaie SS, et al (2010). Ginger ingredients inhibit the development of diethylnitrosoamine induced premalignant phenotype in rat chemical hepatocarcinogenesis model. Biofactors, 36, 483-90.

Mashhadi NS, Ghiasvand R, Askari G, et al (2013). Anti-oxidative and anti-inflammatory effects of ginger in health and physical activity: review of current evidence. Int J Prev Med, 4, 36-42.

Mihara M, Uchiyama M(1978). Determination of malonaldehyde precursor in tissues by thiobarbituric acid test. Anal Biochem, 86, 271-8.

Miranda KM, Espey MG, Wink DA (2001). A rapid, simple spectrophotometric method for simultaneous detection of nitrate and nitrite. Nitric Oxide, 5, 62-71.

Mittal G, Brar AP, Soni G (2006). Impact of hypercholesterolemia on toxicity of N-nitrosodiethylamine: biochemical and histopathological effects. Pharmacol Rep, 58, 413-9.

Mizejewski G (2013). Review of the adenocarcinoma cell surface receptor for human alpha-fetoprotein; proposed identification of a widespread mucin as the tumor cell receptor. Tumor Biol, 34, 1317-36.

Mizejewski G (2014). Alpha-Fetoprotein as a biomarker in immunodeficiency diseases: Relevance to ataxia telangiectasia and related disorders. J Immunodefic Disor, 3, 1. of, $12,2$.

Mizejewski G (2015). Alpha-fetoprotein (AFP) and inflammation: is AFP an acute and/or chronic phase reactant?. Indian J Hematol Blood Transfus, 3: 191. doi:10.4172/23298790.1000191.

Mohd-Yusof Y, Sieh S, Murad N, et al (2002). Anticancer effect of ginger extract (Zingiber officinale) on liver cancer cell lines. Malays J Biochem Mol Biol, 7, 38-42.

Mukkavilli R, Gundala SR, Yang C, et al (2014). Modulation of cytochrome P450 metabolism and transport across intestinal epithelial barrier by ginger biophenolics. PLoS One, 9, e108386.

Nakamura Y, Yoshida C, Murakami A, et al (2004). Zerumbone, a tropical ginger sesquiterpene, activates phase II drug metabolizing enzymes. FEBS Lett, 572, 245-50.

Nanjundaiah SM, Annaiah HN, Dharmesh SM (2011). Gastroprotective effect of Ginger Rhizome (Zingiber officinale) Extract: Role of gallic acid and Cinnamic acid in $\mathrm{H}(+), \mathrm{K}(+)-A T P a s e / H$. pylori inhibition and anti-oxidative mechanism. Evid Based Complement Alternat Med, 2011, 249487.

Nguyen T, Sherratt PJ, Pickett CB (2003). Regulatory mechanisms controlling gene expression mediated by the antioxidant response element. Annu Rev Pharmacol Toxicol, 43, 233-60.

Ohta T, Takahashi M, Ochiai A (2006). Increased protein expression of both inducible nitric oxide synthase and cyclooxygenase-2 in human colon cancers. Cancer lett, 239, 246-53.

Park KK, Chun KS, Lee JM, et al (1998). Inhibitory effects of [6]-gingerol, a major pungent principle of ginger, on phorbol ester-induced inflammation, epidermal ornithine decarboxylase activity and skin tumor promotion in ICR mice. Cancer Lett, 129, 139-44.

Potapovich A, Pastore S, Kostyuk V, et al (2009). $\alpha$-Fetoprotein as a modulator of the pro-inflammatory response of human keratinocytes. Br J Pharmacol, 158, 1236-47.

Prasad S, Tyagi AK (2015a). Ginger and its constituents: role in prevention and treatment of gastrointestinal cancer. Gastroenterol Res Pract, 2015, 142979. 
Prasad S, Tyagi AK (2015b). Ginger and its constituents: role in prevention and treatment of gastrointestinal cancer. Gastroenterol Res Pract, 142979, https://doi. org/10.1155/2015/142979.

Qiu W, Wang X, Leibowitz B, et al (2011). PUMA-mediated apoptosis drives chemical hepatocarcinogenesis in mice. Hepatology, 54, 1249-58.

Rahman MA, Dhar DK, Yamaguchi E, et al (2001). Coexpression of inducible nitric oxide synthase and COX-2 in hepatocellular carcinoma and surrounding liver: possible involvement of COX-2 in the angiogenesis of hepatitis $\mathrm{C}$ virus-positive cases. Clin Cancer Res, 7, 1325-32.

Ramos-Gomez M, Kwak M-K, Dolan PM, et al (2001). Sensitivity to carcinogenesis is increased and chemoprotective efficacy of enzyme inducers is lost in nrf2 transcription factor-deficient mice. Proc Natl Acad Sci U S A, 98, 3410-5.

Rani MP, Padmakumari KP, Sankarikutty B, et al (2011). Inhibitory potential of ginger extracts against enzymes linked to type 2 diabetes, inflammation and induced oxidative stress. Int J Food Sci Nutr, 62, 106-10.

Reitman S, Frankel S (1957). A colorimetric method for the determination of serum glutamic oxalacetic and glutamic pyruvic transaminases. Am J Clin Pathol, 28, 56-63.

Sadik NA, EL-Maraghy SA, Ismail MF (2008). Diethylnitrosamine-induced hepatocarcinogenesis in rats: possible chemoprevention by blueberries. Afr J Biochem Res, 2, 081-7.

Sayed-Ahmed MM, Aleisa AM, Al-Rejaie SS, et al (2010). Thymoquinone attenuates diethylnitrosamine induction of hepatic carcinogenesis through antioxidant signaling. Oxid Med Cell Longev, 3, 254-61.

Sell S, Becker F, Leffert H, et al (1983). Alphafetoprotein as a marker for early events and carcinoma development during chemical hepatocarcinogenesis. In 'Application of Biological Markers to Carcinogen Testing', Eds Springer, pp 271-93.

Shivashankara A, Haniadka R, Fayad R, et al (2013). Hepatoprotective effects of Zingiber officinale Roscoe (Ginger): A review. In 'Bioactive Food as Dietary Interventions for Liver and Gastrointestinal Disease', Eds Elsevier, pp 657-71.

Skog K (2002). Problems associated with the determination of heterocyclic amines in cooked foods and human exposure. Food Chem Toxicol, 40, 1197-203.

Surh YJ (2003). Cancer chemoprevention with dietary phytochemicals. Nat Rev Cancer, 3, 768-80.

Taha MM, Abdul AB, Abdullah R, et al (2010). Potential chemoprevention of diethylnitrosamine-initiated and 2-acetylaminofluorene-promoted hepatocarcinogenesis by zerumbone from the rhizomes of the subtropical ginger (Zingiber zerumbet). Chem Biol Interact, 186, 295-305.

Tessitore L (1998). Hepatocellular carcinoma is induced by a subnecrogenic dose of diethylnitrosamine in previously fasted-refed rats. Nutr Cancer, 32, 49-54.

Tessitore L, Tomasi C, Greco M, et al (1996). A subnecrogenic dose of diethylnitrosamine is able to initiate hepatocarcinogenesis in the rat when coupled with fasting/ refeeding. Carcinogenesis, 17, 289-92.

Tjendraputra E, Tran VH, Liu-Brennan D, et al (2001). Effect of ginger constituents and synthetic analogues on cyclooxygenase- 2 enzyme in intact cells. Bioorg Chem, 29, 156-63.

Uehara T, Pogribny IP, Rusyn I (2014). The DEN and CCl4 -induced Mouse model of fibrosis and inflammation-associated hepatocellular carcinoma. Curr Protoc Pharmacol, 66, 1-10.

Unsal V, Belge-Kurutas E (2017). Experimental Hepatic Carcinogenesis: Oxidative Stress and Natural Antioxidants.
Open Access Maced J Med Sci, 5, 686-91.

van Breemen RB, Tao Y, Li W (2011). Cyclooxygenase-2 inhibitors in ginger (Zingiber officinale). Fitoterapia, 82, 38-43.

Vasquez-Garzon VR, Macias-Perez JR, Jimenez-Garcia MN, et al (2013). The chemopreventive capacity of quercetin to induce programmed cell death in hepatocarcinogenesis. Toxicol Pathol, 41, 857-65.

Wu T (2006). Cyclooxygenase-2 in hepatocellular carcinoma. Cancer Treat Rev, 32, 28-44.

Yoshikawa M, Yamaguchi S, Kunimi K, et al (1994). Stomachic principles in ginger. III. An anti-ulcer principle, 6-gingesulfonic acid, and three monoacyldigalactosylglycerols, gingerglycolipids $\mathrm{A}, \mathrm{B}$, and $\mathrm{C}$, from Zingiberis Rhizoma originating in Taiwan. Chem Pharm Bull (Tokyo), 42, 1226-30.

Yoshimi N, Wang A, Morishita Y, et al (1992). Modifying effects of fungal and herb metabolites on azoxymethaneinduced intestinal carcinogenesis in rats. Jpn J Cancer Res, 83, 1273-8.

Yusof YA, Ahmad N, Das S, et al (2008). Chemopreventive efficacy of ginger (Zingiber officinale) in ethionine induced rat hepatocarcinogenesis. Afr J Tradit Complement Altern Med, 6, 87-93.

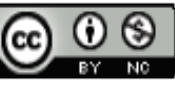

This work is licensed under a Creative Commons AttributionNon Commercial 4.0 International License. 